\title{
Optimization and evaluation of alkali-pretreated Paeonia ostii seed coats as adsorbent for the removal of $\mathrm{MB}$ from aqueous solution
}

\author{
Qiong Liu', ${ }^{1,}$, Tao Li $^{1}$, Shaowen Zhang ${ }^{2}$, Lingbo Qu', Baozeng Ren ${ }^{1 *}$ \\ ${ }^{1}$ School of Chemical Engineering and Energy, Zhengzhou University, Zhengzhou, Henan 450001, P. R. China \\ ${ }^{2}$ School of Environmental Engineering and Chemistry, Luoyang Institute of Science and Technology, Luoyang, Henan \\ 471023, P. R. China \\ *Corresponding author: e-mail: renbz@zzu.edu.cn
}

\begin{abstract}
A novel efficient adsorbent, alkali-pretreated Paeonia ostii seed coats (AP-PSC), was investigated for the removal of methylene blue (MB) dye from solution. Orthogonal array design was applied to optimize the process parameters viz. alkali concentration, liquid-solid ratio (LSR) and pretreatment time. The results revealed that the optimal pretreatment conditions were at $0.8 \%(\mathrm{w} / \mathrm{w}) \mathrm{NaOH}$ with LSR of $0.35 \mathrm{~L} \mathrm{~g}^{-1}$ treating for $50 \mathrm{~min}$. Equilibrium and kinetic studies indicated that Langmuir isotherm and Pseudo-second-order models described the experimental data well. The maximum adsorption capability was of $368.2 \mathrm{mg} \mathrm{g}^{-1}$ for $\mathrm{MB}$ at $25^{\circ} \mathrm{C}$. Thermodynamic parameters suggested that the AP-PSC adsorption process was physical, endothermic and spontaneous. Furthermore, the adsorption process was influenced by several interactive mechanisms, including ion-exchange, as well as Van der Waals forces and hydrogen bonds that occur concomitantly. It was concluded that AP-PSC may be potential as an efficient adsorbent to remove MB from solution.
\end{abstract}

Keywords: Alkali-pretreated Paeonia ostii seed coats, Adsorption, Methylene blue, Mechanism.

\section{INTRODUCTION}

With the increased demand for textile products, a substantial number of synthetic dyes are discharged into aquatic environments without adequate treatment, which has been a serious global problem of great concern $^{1}$. Over the past decades, several physicochemical and biological approaches have been developed to treat dyestuffs wastewater, like adsorption techniques, coagulation/flocculation processes, oxidation treatment, ion exchange and biological degradation ${ }^{2}$. Among these, the adsorption technique has been recognized as one of the top control methods owing to its economic feasibility, high efficiency, simplicity of design and operation ${ }^{3}$. Agricultural wastes (AWs), which are the most abundant renewable resources on earth, have arisen widely attention of domestic and foreign scholars ${ }^{4}$. A large variety of AWs, including rice husk, wheat bran, rye straw, corncob, cassava peel, sugarcane pulp, coconut coir, coffee wastes, cucumis sativus peel, citrus limetta peel have been examined for their ability to removal of dyes from water and wastewater ${ }^{5-6}$. Nevertheless, the application of untreated AWs has obvious disadvantages such as low adsorption capacity and high solubility ${ }^{7}$. To overcome such problems, chemical modifications using alkali solutions (e.g., sodium hydroxide), acid solutions (sulfuric acid, citric acid, etc.), mineral (e.g., calcium chloride), oxidizing agent (e.g., hydrogen peroxide) or organic compounds (e.g., formaldehyde) have been investigated and shown to enhance the removal efficiency of various contaminants in aqueous solutions $\mathrm{s}^{8-9}$.

Paeonia ostii (Paeonia section Moutan DC.) is a kind of ornamental, officinal and oil plant resource with high economic value ${ }^{\mathbf{1 0}}$. Its seeds coats are often discarded as waste. The use of Paeonia ostii seeds coats (PSC) as adsorbents can not only take full advantage of the renewable resource, but also minimize environmental pollution. To the best of authors' knowledge, there is no report on the application of PSC-based adsorbent for the removal of pollutants from aqueous solution. According to the preliminary study, the maximum adsorption capability of PSC for MB was found to be $74.01 \mathrm{mg} \mathrm{g}^{-1}$ at $25^{\circ} \mathrm{C}$.

The objective of present study was to investigate the feasibility of alkali-pretreated Paeonia ostii seed coats (AP-PSC) as an adsorbent to remove methylene blue (MB) dye from aqueous solution. The pretreatment was optimized by $\mathrm{L}_{9}(3)^{4}$ orthogonal array design and three parameters were taken into consideration, including $\mathrm{NaOH}$ concentration, treatment time, and liquid-solid ratio (LSR). The structural and morphology changes of PSC after the pretreatment were analyzed by scanning electron micrograph (SEM) and Fourier transform infrared spectroscopy (FTIR). The feasibility of AP-PSC as an adsorbent was evaluated by adsorption kinetics and equilibrium isotherm experiments. The thermodynamic parameters $\left(\Delta \mathrm{H}^{0}, \Delta \mathrm{S}^{0}\right.$ and $\left.\Delta \mathrm{G}^{0}\right)$ and activation energy $\left(E_{a}\right)$ for sorption studies were also confirmed to provide vital information to determine the mechanism and optimize operating conditions, thereby improving the adsorption properties.

\section{EXPERIMENTAL}

\section{Material}

$\mathrm{MB}\left(\mathrm{C}_{16} \mathrm{H}_{18} \mathrm{ClN}_{3} \mathrm{~S} \cdot 3 \mathrm{H}_{2} \mathrm{O}, \geq 90 \%\right)$ was purchased from Aladdin Industrial Corporation (Shanghai, China). The stock solution of MB (2000 mg L $\left.\mathrm{m}^{-1}\right)$ was prepared and diluted to the required concentrations for each test. All other chemicals used in the present work were of analytical grade.

\section{Adsorbent preparation}

Paeonia ostii seed coats (PSC) were collected from Luoyang National Tree Peony Collection located in Luoyang City, Henan Province, China. Prior to use, the PSC were washed several times with deionized water and dried in open sunlight for 3 days. The product was crushed, sieved in the size range of $0.5 \sim 0.8 \mathrm{~mm}$. The ground PSC were subjected to alkali pretreatment un- 
der the following conditions: $\mathrm{NaOH}$ concentration $(0.2$, 0.5 , and $0.8 \%, \mathrm{w} / \mathrm{w})$, liquid-solid ratio $(1: 20,4: 20$, and 7:20 L g $\left.{ }^{-1}, \mathrm{v} / \mathrm{w}\right)$ and pretreatment time (10, 30, and 50 min). The experiment was preformed in a thermostatic oscillator at $30^{\circ} \mathrm{C}$, and the stirring speed was $165 \mathrm{rpm}$ to keep the alkali solution in contact with PSC during pretreatment. After pretreatment, the residues were rinsed with deionized water, filtered and then dried in the oven at $60^{\circ} \mathrm{C}$ until to a constant weight. Under optimized conditions, the alkali-pretreated Paeonia ostii seed coats was obtained and designated as AP-PSC.

\section{Experimental design and statistical analysis}

Orthogonal array design (OAD) was adopted to determine the optimal conditions of pretreatment for the removal of $\mathrm{MB}$ dye from aqueous solution. $\mathrm{NaOH}$ concentration (A), liquid-solid ratio (B) and pretreatment time (C), were chosen as the processing factors and the adsorption capacity for the MB dye was employed as the evaluation indicator. For each individual factor three levels were considered. A blank factor was used as a dummy for error estimation. The OAD $9\left(3^{4}\right)$ matrix used for optimization and level settings of individual factor are presented in Table 1.

All samples were tested in triplicate and statistical analysis was conducted by employing SPSS 21.0 software. Data were expressed as the mean \pm standard deviation. The OAD results were analyzed by one-way analysis of variance (ANOVA). Differences were considered significant at $\mathrm{p}<0.05$.

\section{Characterization of PSC and AP-PSC}

The surface morphology was identified by Focused ion beam scanning electron microscope (Auriga FIB-SEM, Zeiss, German). The FT-IR spectra were acquired using FT-IR spectrometer (Nexus-470, Nicolet, USA) in the wave number range of $4000-400 \mathrm{~cm}^{-1}$.

\section{Batch adsorption experiments}

Batch adsorption experiments were carried out by mixing $0.01 \mathrm{~g}$ of samples with $20 \mathrm{ml}$ of MB solutions in $50 \mathrm{ml}$ stopped conical flasks at three different temperatures $\left(25,35\right.$ and $\left.45^{\circ} \mathrm{C}\right)$. The solution $\mathrm{pH}$ was kept at its initial value (5.3), and was not controlled during the experiment. In the kinetics experiments, $330 \mathrm{mg} \mathrm{L}^{-1} \mathrm{MB}$ solution was used. The sorption time was varied between $1 \mathrm{~h}$ and $8 \mathrm{~h}$. In case of isotherm experiments, the same amount of sample $(0.01 \mathrm{~g})$ was added in $20 \mathrm{ml}$ of various concentrations $\left(150-600 \mathrm{mg} \mathrm{L}^{-1}\right) \mathrm{MB}$ solution for $12 \mathrm{~h}$. Good contact was made between sample and MB solution by agitating at $165 \mathrm{rpm}$ in a thermostatic oscillator. After the required time, the mixture was centrifuged at $8000 \mathrm{rpm}$ for $20 \mathrm{~min}$ and the supernatant solutions were analyzed for the residual $\mathrm{MB}$ concentration using a UV-Vis spectrophotometer (UV-2300II, Techcomp, China) at $\lambda_{\text {max }} 665 \mathrm{~nm}$. The amount of adsorption (q) was calculated by the following equation:

$q=\frac{\left(C_{0}-C_{e}\right) V}{m}$

Where, $\mathrm{C}_{0}$ and $\mathrm{C}_{\mathrm{e}}$ are the initial and equilibrium $\mathrm{MB}$ concentrations $\left(\mathrm{mg} \mathrm{L}^{-1}\right)$, respectively. $\mathrm{V}$ is the volume of solution (L), and $\mathrm{m}$ is the amount of sample used $(\mathrm{g})$. All assays were conducted in triplicate and the mean values were reported.

\section{RESULTS AND DISCUSSION}

\section{Analysis of orthogonal array design}

On the basis of single factor experiments (data not shown), the OAD $9\left(3^{4}\right)$ matrix was applied to optimize the pretreatment conditions. The response of each trial is listed in Table 1. Effect of the processing parameters on the indicator was determined by means of range $(\mathrm{R})$ analysis (Table 2) and ANOVA (Table 3). Results of the range analysis show that the influence of parameters on the adsorption capacity for $\mathrm{MB}$ decreased in the order

Table 1. Factors and levels of OAD 9 (34) and experimental results of pretreatment process

\begin{tabular}{|c|c|c|c|c|c|}
\hline \multirow[b]{2}{*}{$\begin{array}{l}\text { Test } \\
\text { No. }\end{array}$} & \multicolumn{4}{|c|}{ Factors / Levels } & Experiment results \\
\hline & $\begin{array}{c}(\mathrm{A}) \\
\mathrm{NaOH} \text { concentration } \\
{[\mathrm{w} / \mathrm{w}, \%]}\end{array}$ & $\begin{array}{c}\text { (B) } \\
\text { liquid-solid ratio } \\
{\left[\mathrm{v} / \mathrm{w}, \mathrm{Lg}^{-1}\right]}\end{array}$ & $\begin{array}{c}(\mathrm{C}) \\
\text { Pretreatment time [min] }\end{array}$ & $\begin{array}{l}\text { (D) } \\
\text { Blank }\end{array}$ & $\begin{array}{l}\text { Adsorption capacity for } \\
\text { MB dye }\left[\mathrm{mg} \mathrm{g}^{-1}\right]\end{array}$ \\
\hline 1 & $0.2(1)$ & $0.05(1)$ & $10(1)$ & (1) & $128.4 \pm 3.0$ \\
\hline 2 & $0.2(1)$ & $0.2(2)$ & $30(2)$ & (2) & $189.4 \pm 3.3$ \\
\hline 3 & $0.2(1)$ & $0.35(3)$ & $50(3)$ & (3) & $229.9 \pm 4.1$ \\
\hline 4 & $0.5(2)$ & $0.05(1)$ & $30(2)$ & (3) & $244.6 \pm 2.4$ \\
\hline 5 & $0.5(2)$ & $0.2(2)$ & $50(3)$ & (1) & $272.1 \pm 2.1$ \\
\hline 6 & $0.5(2)$ & $0.35(3)$ & $10(1)$ & (2) & $208.6 \pm 2.8$ \\
\hline 7 & $0.8(3)$ & $0.05(1)$ & $50(3)$ & (2) & $271.3 \pm 2.6$ \\
\hline 8 & $0.8(3)$ & $0.2(2)$ & $10(1)$ & (3) & $227.8 \pm 5.0$ \\
\hline 9 & $0.8(3)$ & $0.35(3)$ & $30(2)$ & (1) & $277.3 \pm 2.8$ \\
\hline
\end{tabular}

Table 2. Range (R) analysis on indicator parameter obtained from the OAD 9 (34) experiment

\begin{tabular}{|l|c|c|c|c|}
\hline Indicator & $\begin{array}{c}(\mathrm{A}) \\
\mathrm{NaOH} \text { concentration } \\
{[\mathrm{w} / \mathrm{w}, \%]}\end{array}$ & $\begin{array}{c}(\mathrm{B}) \\
\left.\text { liquid-solid ratio [v/w, } \mathrm{L} \mathrm{g}^{-1}\right]\end{array}$ & $\begin{array}{c}(\mathrm{C}) \\
\text { Pretreatment time [min] }\end{array}$ & $\begin{array}{c}(\mathrm{D}) \\
\text { Blank }\end{array}$ \\
\hline \multicolumn{5}{|c|}{ Adsorption capacity for MB [mg g-1] } \\
\hline $\mathrm{K}_{1}$ & $182.6 \pm 3.5$ & $214.8 \pm 2.6$ & $188.3 \pm 3.6$ & $225.9 \pm 2.6$ \\
\hline $\mathrm{K}_{2}$ & $241.8 \pm 2.4$ & $229.8 \pm 3.5$ & $237.1 \pm 2.8$ & $223.1 \pm 2.9$ \\
\hline $\mathrm{K}_{3}$ & $258.8 \pm 3.5$ & $238.6 \pm 3.3$ & $257.8 \pm 2.9$ & $234.1 \pm 3.8$ \\
\hline $\mathrm{R}$ & 76.2 & 23.8 & 69.5 & 11.0 \\
\hline Best level & $\mathrm{A}_{3}$ & $\mathrm{~B}_{3}$ & $\mathrm{C}_{3}$ & \\
\hline
\end{tabular}

$\mathrm{K}_{1}, \mathrm{~K}_{2}$ and $\mathrm{K}_{3}$ are the average scores of level $1-3$ for each factor, respectively.

$\mathrm{R}$ is estimated by the difference between the highest and the lowest of the average scores. 
Table 3. Results of ANOVA on indicator parameter obtained from the OAD 9 (34) experiment

\begin{tabular}{|c|c|c|c|c|c|c|}
\hline Indicator & Source & d.f. & SS & $\mathrm{F}$ & $\mathrm{P}$ & Sig. \\
\hline \multicolumn{7}{|l|}{ Adsorption capacity for MB [mg g ${ }^{-1]}$} \\
\hline & $A$ & 2 & 9606.3 & 49.1 & 0.0200 & Significant \\
\hline & $B$ & 2 & 871.1 & 4.5 & 0.180 & insignificant \\
\hline & C & 2 & 7642.1 & 39.1 & 0.0300 & Significant \\
\hline & Error & 2 & 195.7 & & & \\
\hline
\end{tabular}

d.f.: degrees of freedom; SS: Sum of squares; F: $F$ test; P: probability.

of: $\mathrm{A}(\mathrm{NaOH}$ concentration $)>\mathrm{C}$ (pretreatment time) $>$ B (liquid-solid ratio). To verify whether the effect of individual factors on evaluation indicator was statistically significant, the ANOVA was employed to interpret the experiment data based on Fischer's test (F-value). Accordingly, the larger F-value is suggestive of the greater significant effect the factor made. The analysis of variance revealed that the most significant variable $(p<0.05)$ was found to be $\mathrm{NaOH}$ concentration, followed by pretreatment time. By contrast, liquid-solid ratio was insignificant $(p>0.05)$ for the removal of MB dye. The comprehensive analysis indicated that the optimal pretreatment process was attained at a combination of the following factors: $\mathrm{NaOH}$ concentration of $0.8 \%(\mathrm{w} / \mathrm{w})$, pretreatment time of $50 \mathrm{~min}$, and liquid-solid ratio of $0.35 \mathrm{~L} \mathrm{~g}^{-1}$ i.e. $\mathrm{A}_{3} \mathrm{C}_{3} \mathrm{~B}_{3}$.

\section{Characterization of PSC and AP-PSC}

The FT-IR spectra of PSC, AP-PSC and AP-PSC adsorbed with MB (AP-PSC-MB) were plotted in Fig. 1. As displayed, PSC has a number of absorption peaks, reflecting the complex nature of the material examined. After alkali pretreatment, only a few such as peaks at $1732 \mathrm{~cm}^{-1}$ (C=O stretching), $1515 \mathrm{~cm}^{-1}$ (aromatic skeletal vibration) and $1245 \mathrm{~cm}^{-1}$ (C-O stretching) were absent from the PSC skeleton, probably due to the dissolution/ removal trends of hemicelluloses and lignin ${ }^{11-14}$. In the case of AP-PSC after MB adsorption, there are some peaks that were shifted or disappeared $\left(3416 \mathrm{~cm}^{-1}(\mathrm{OH}\right.$ stretching); $2932 \mathrm{~cm}^{-1}$ (C-H stretching); $1623 \mathrm{~cm}^{-1}(\mathrm{C}=\mathrm{O}$ stretching); $1420 \mathrm{~cm}^{-1}$ (aromatic skeletal vibration)) and

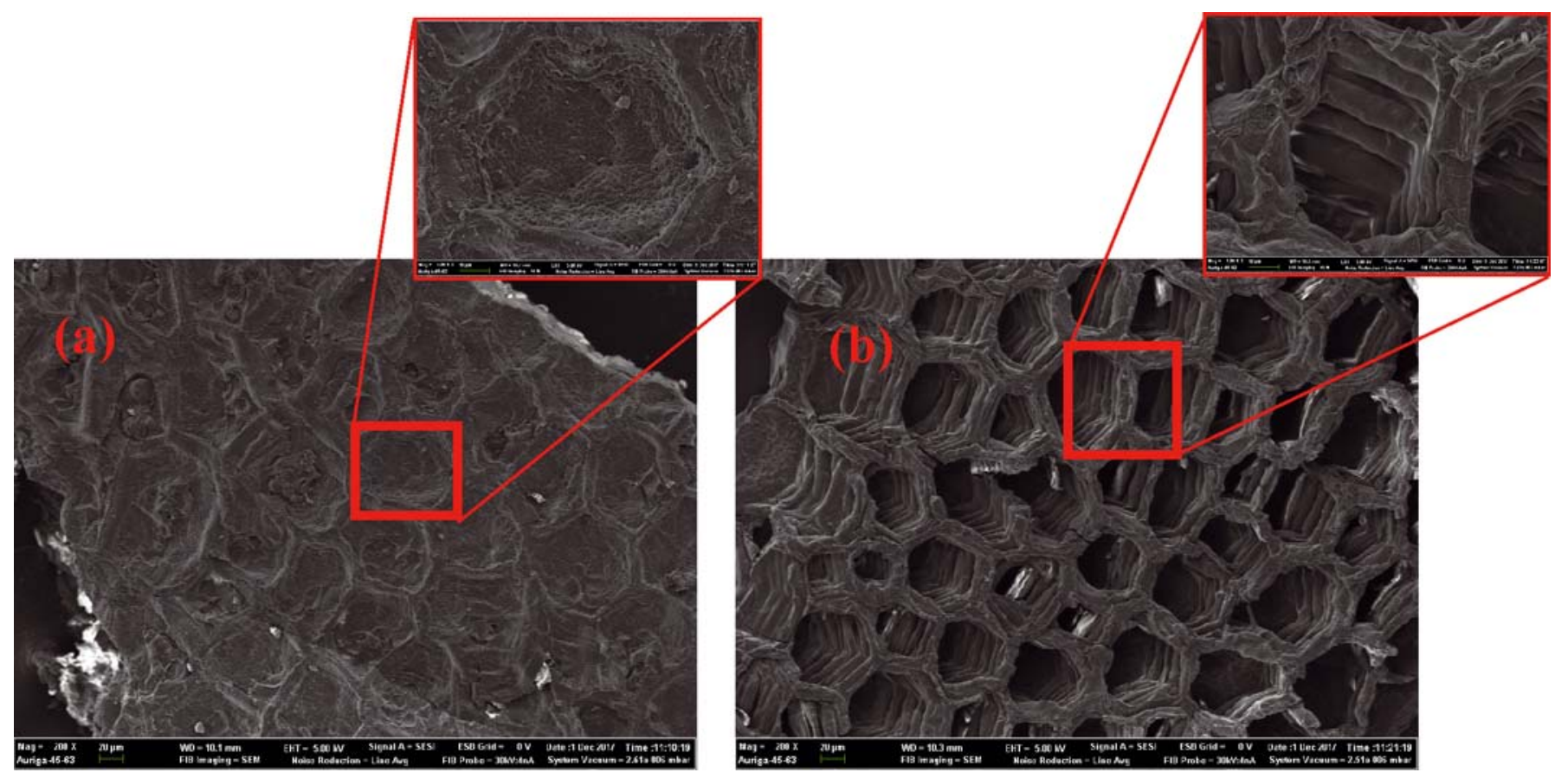

new peaks (1489 $\mathrm{cm}^{-1}\left(\mathrm{CH}_{2}\right.$ deformation vibration); 1245 $\mathrm{cm}^{-1}$ (Ar-N deformation vibration)) were also detected. These changes observed in the spectra indicated the possible involvement of those functional groups on the surface of AP-PSC in MB adsorption ${ }^{15}$.

To investigate the changes imparted in the surface morphology by the pretreatment strategy, SEM micrographs of PSC and AP-PSC are recorded (Fig. 2). As can be seen from the chart, the pores from the surface of PSC were opened up after the alkaline treatment. It might be due to the removal of some low-molecular weight compounds, or to the degradation of lignin and polysaccharides from the biomass skeleton ${ }^{\mathbf{1 6}}$. Obviously, the larger porosity and accessible surface area (data not

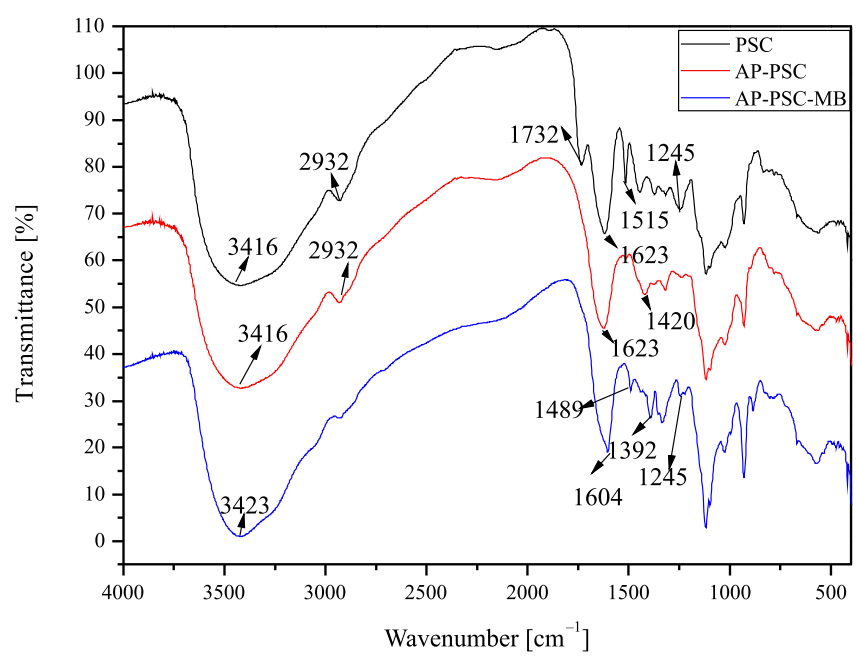

Figure 1. FT-IR spectra of PSC, AP-PSC and AP-PSC-MB

Figure 2. SEM images of (a) PSC and (b) AP-PSC 
shown) were beneficial of adsorption on the surface of AP-PSC, thereby increasing the MB uptake.

\section{Batch adsorption studies}

\section{Adsorption kinetics}

The effect of contact time on adsorption process was investigated at the temperatures of 25,35 and $45^{\circ} \mathrm{C}$. As shown in Fig. 3, initially, the adsorption capacity of AP-PSC for MB increases sharply with the prolongation of time and thereafter becomes constant. Meanwhile, a slight increase in $\mathrm{MB}$ removal with the temperature indicates that the adsorption process is endothermic.

To understant the MB adsorption process on AP-PSC, the experiments data were fitted to pseudo-first order, pseudo-second order, Elovich, and Weber Moris intraparticle kinetic models following the adsorption equations given below ${ }^{17}$ :

Pseudo-first order equation: $q_{t}=q_{e}\left(1-e^{-k_{1} t}\right)$

Pseudo-second order equation: $q_{t}=\frac{k_{2} q_{e}^{2} t}{1+k_{2} q_{e} t}$

Elovich equation: $q_{t}=\frac{1}{\beta} \ln (\alpha \beta)+\frac{1}{\beta} \ln t$

Intraparticle diffusion equation: $q_{t}=k_{i d} t^{0.5}+C_{i}$

Where, $\mathrm{q}_{\mathrm{e}}$ and $\mathrm{q}_{\mathrm{t}}$ are the adsorption capacity per unit weight of samples $\left(\mathrm{mg} \mathrm{g}^{-1}\right)$ at equilibrium and at time $\mathrm{t}$, respectively; $\mathrm{k}_{1}\left(\mathrm{~min}^{-1}\right)$ and $\mathrm{k}_{2}\left(\mathrm{~g} \mathrm{mg}^{-1} \mathrm{~min}^{-1}\right)$ are the pseudo-first order and the pseudo-second order rate constant, respectively; $\alpha\left(\mathrm{mg} \mathrm{g}^{-1} \mathrm{~min}^{-1}\right)$ is the initial adsorption rate and $\beta\left(\mathrm{g} \mathrm{mg}^{-1}\right)$ is the extent of surface coverage and activation energy involved in the chemisorption; $\mathrm{k}_{\mathrm{id}}\left(\mathrm{mg} \mathrm{g}^{-1} \mathrm{~min}^{-0.5}\right)$ is the intraparticle diffusion rate constant, $\mathrm{C}_{\mathrm{i}}\left(\mathrm{mg} \mathrm{g}^{-1}\right)$ is the constant associated with the thickness of boundary layer. Higher value of constant $C_{i}$ indicates a greater effect on the limiting boundary layer.

The fitting results are illustrated in Fig. 3. The corresponding parameters, as well as correlation coefficients $\left(\mathrm{R}^{2}\right)$ and Chi-square test $\left(\chi^{2}\right)$ are listed in Table 4. According to the results, the pseudo-second-order kinetic model had a better fit to the experimental data, considering its highest $\mathrm{R}^{2}$ value and the lowest $\chi^{2}$ value, followed by the Elovich model. In addition, the adsorption capacities $\left(\mathrm{q}_{\mathrm{e}}\right)$ calculated by pseudo-second-order kinetic model were the most similar to the experimental data $\left(\mathrm{q}_{\mathrm{e}-\exp }\right)$ compared with the other models for all assessed tem-
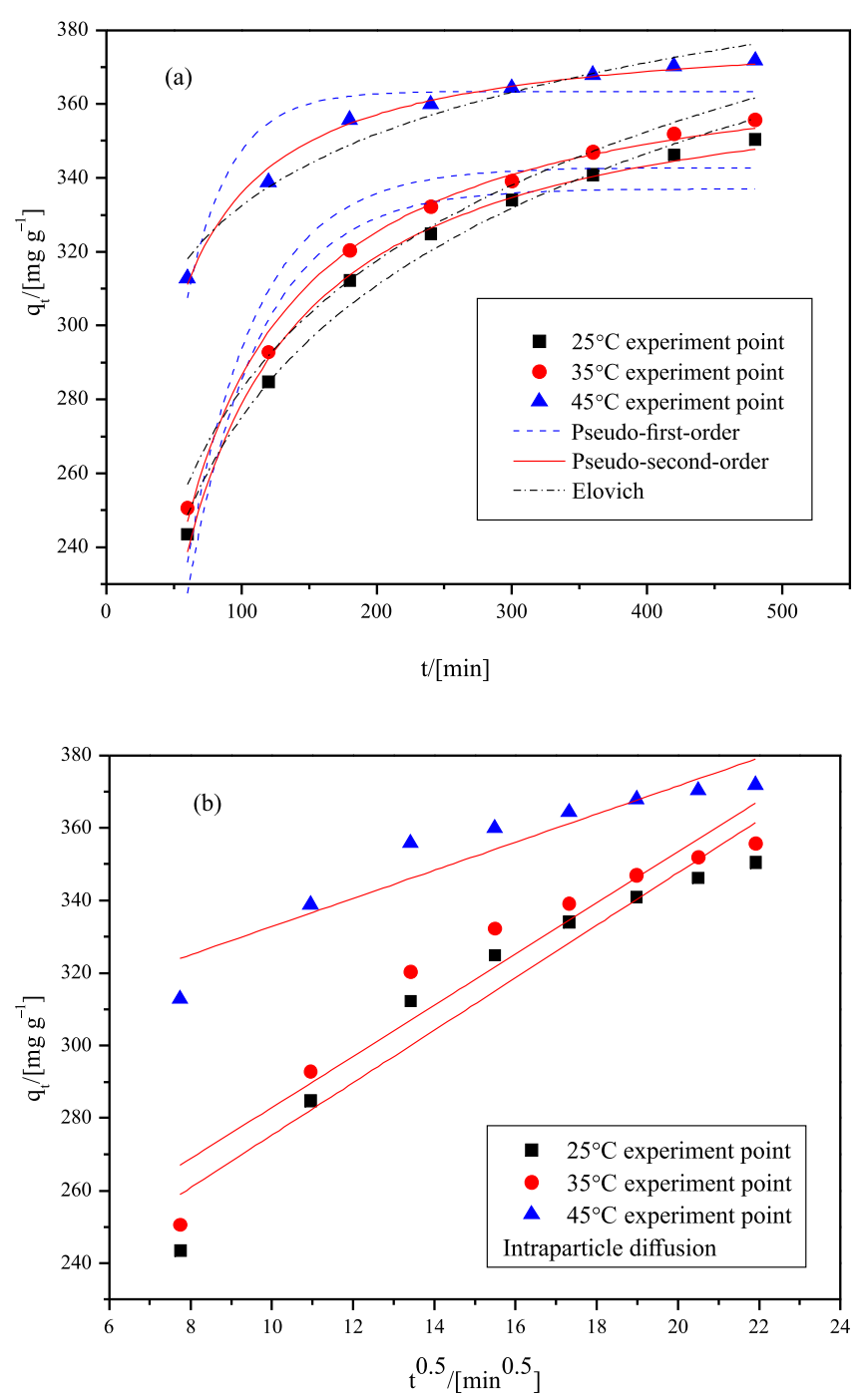

Figure 3. Nonlinear fits of Pseudo-first-order, Pseudo-second-order and Elovich kinetic models (a) and linear fits of intraparticle diffusion model (b) for the MB adsorption at 25,35 and $45^{\circ} \mathrm{C}$

Table 4. Parameters and determination coefficients of the kinetic models for MB adsorption onto AP-PSC

\begin{tabular}{|c|c|c|c|c|}
\hline \multirow{2}{*}{ Model } & \multirow{2}{*}{ Parameters } & \multicolumn{3}{|c|}{ Temperature $\left[{ }^{\circ} \mathrm{C}\right]$} \\
\hline & & 25 & 35 & 45 \\
\hline \multirow{5}{*}{ Pseudo-first-order } & $\mathrm{k}_{1} /\left[\mathrm{min}^{-1}\right]$ & 0.0187 & 0.0194 & 0.0312 \\
\hline & $\mathrm{q}_{\mathrm{e}} /\left[\mathrm{mg} \mathrm{g}^{-1}\right]$ & 337.1 & 342.9 & 363.5 \\
\hline & $q_{e-\exp }$ & 372.5 & 376.2 & 380.8 \\
\hline & $R^{2}$ & 0.867 & 0.874 & 0.806 \\
\hline & $x^{2}$ & 3.64 & 3.22 & 1.35 \\
\hline \multirow{4}{*}{ Pseudo-second-order } & $\mathrm{k}_{2} /\left[\mathrm{g} \mathrm{mg}^{-1} \mathrm{~min}^{-1}\right]$ & $8.03 \times 10^{-5}$ & $8.41 \times 10^{-5}$ & $1.94 \times 10^{-4}$ \\
\hline & $\mathrm{q}_{\mathrm{e}} /\left[\mathrm{mg} \mathrm{g}^{-1}\right]$ & 372.0 & 376.7 & 381.3 \\
\hline & $R^{2}$ & 0.991 & 0.993 & 0.991 \\
\hline & $x^{2}$ & 0.269 & 0.191 & 0.0638 \\
\hline \multirow{4}{*}{ Elovich } & $\alpha /\left[\mathrm{mg} \mathrm{g}^{-1} \min ^{-1}\right]$ & 106.8 & 137.4 & 40184 \\
\hline & $\beta /\left[\mathrm{g} \mathrm{mg}^{-1}\right]$ & 0.0194 & 0.0198 & 0.0357 \\
\hline & $R^{2}$ & 0.983 & 0.976 & 0.953 \\
\hline & $x^{2}$ & 0.455 & 0.586 & 0.327 \\
\hline \multirow[t]{4}{*}{ Intra-particle diffusion } & $\mathrm{k}_{\mathrm{id}} /\left[\mathrm{mg} \mathrm{g}^{-1} \mathrm{~min}^{-0.5}\right]$ & 7.24 & 7.05 & 3.88 \\
\hline & $\mathrm{C}_{\mathrm{i}} /\left[\mathrm{mg} \mathrm{g}^{-1}\right]$ & 202.9 & 212.4 & 294.0 \\
\hline & $\mathrm{R}^{2}$ & 0.916 & 0.904 & 0.863 \\
\hline & $x^{2}$ & 2.30 & 2.49 & 0.971 \\
\hline
\end{tabular}

Note: $\chi^{2}=\sum_{n=1}^{n} \frac{\left(q-q_{c}\right)^{2}}{q}, \mathrm{q}$ and $\mathrm{q}_{\mathrm{c}}$ are the experimental value and calculated value according the model, respectively. 
peratures. Applicability of pseudo-second-order kinetic model implied that the rate-controlling step was chemisorption involving the exchange/sharing of electrons ${ }^{18}$. The Elovich model further suggests that the chemical adsorption occurs on the energetically heterogeneous surface of AP-PSC. Besides, the pseudo-first-order kinetic model was not suitable to describe the experiment data due to the lower $\mathrm{R}^{2}$ value and higher $\chi^{2}$ value. Moreover, Weber Morris intraparticle model was applied to identify the involved diffusion mechanisms. From Fig. 3 (b), it could be confirmed that the intraparticle diffusion was not the only rate-limiting step because the plots of $q_{t}$ versus $t^{1 / 2}$ did not pass through the origin. Again since $C_{i} \neq 0$ hence it was suggested that the film diffusion be also a possible involvement in the mechanism of adsorption ${ }^{19}$. Thus, the adsorption process of MB dye on AP-PSC could be controlled jointly by intraparticle and film diffusion mechanisms.

\section{Adsorption equilibrium}

Equilibrium experiments were performed to analyze the influence of initial concentration on adsorption at different temperatures $\left(25,35\right.$ and $\left.45^{\circ} \mathrm{C}\right)$. According to Fig. 4, an increase in the adsorption capacity with the initial concentration could be observed due to the increase in the probability of contact between the MB molecules and the AP-PSC adsorbent surface.

The equilibrium data were fitted to non-linear Langmuir, Freundlich and Koble-Corrigan isotherm models using the following equations ${ }^{20}$.

Langmuir isotherm: $q_{e}=\frac{q_{m} K_{L} C_{e}}{1+K_{L} C_{e}}$

Freudlich isotherm: $q_{e}=K_{F} C_{e}^{1 / n}$

Koble-Corrigan isotherm: $q_{e}=\frac{A C_{e}^{n}}{1+B C_{e}^{n}}$

Where, the Langmuir constants $\mathrm{q}_{\mathrm{m}}\left(\mathrm{mg} \mathrm{g}^{-1}\right)$ and $\mathrm{K}_{\mathrm{L}}$ $\left(\mathrm{L} \mathrm{mg}^{-1}\right)$ represent the theoretical maximum adsorption capacity per unit weight adsorbent and Langmuir constant related to the energy of adsorption, respectively; while $\mathrm{C}_{\mathrm{e}}\left(\mathrm{mg} \mathrm{L}^{-1}\right)$ is the equilibrium concentration of MB solution and $\mathrm{q}_{\mathrm{e}}\left(\mathrm{mg} \mathrm{g}^{-1}\right)$ is the equilibrium adsorption capacity per unit weight adsorbent, respectively; $\mathrm{K}_{\mathrm{F}}(\mathrm{mg}$ $\left.\mathrm{g}^{-1}\left(\mathrm{~L} \mathrm{mg}^{-1}\right)^{1 / \mathrm{n}}\right)$ and $1 / \mathrm{n}$ are related to the adsorption capacity of the adsorbent and adsorption intensity, respectively; A, B and $\mathrm{n}$ are the Koble-Corrigan isotherm constants, which are obtained from non-linear regressive analysis of Koble-Corrigan isotherm.

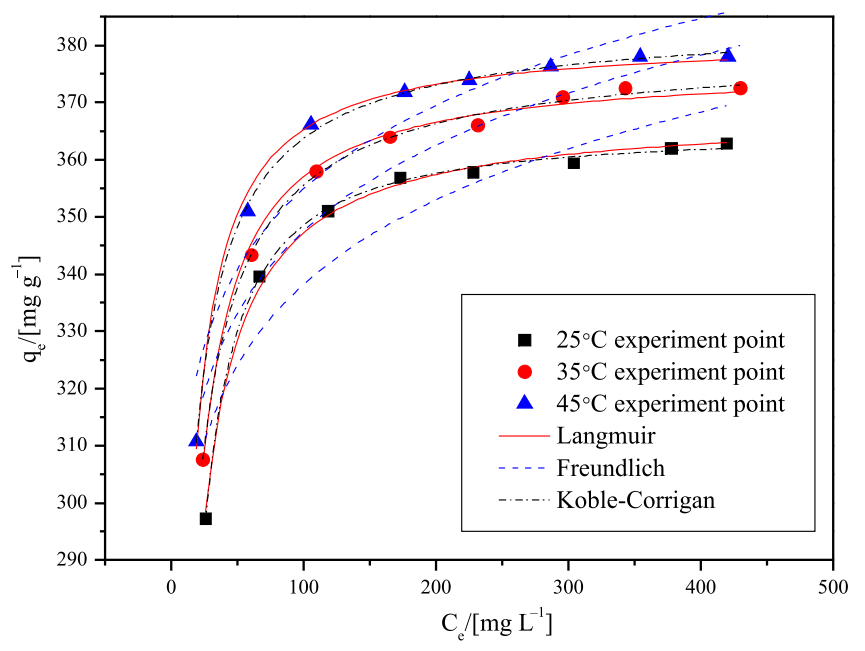

Figure 4. Nonlinear fits of isotherm models for $\mathrm{MB}$ adsorption at 25,35 and $45^{\circ} \mathrm{C}$

The fitted data are shown in Fig. 4. The isotherm parameters, correlation coefficients $\left(\mathrm{R}^{2}\right)$ and Chi-square test $\left(\chi^{2}\right)$ are displayed in Table 5. As can be observed from Fig. 4 and Table 5, Koble-Corrigan model showed the highest $\mathrm{R}^{2}$ values and the lowest $\chi^{2}$ values, indicating better fits to the experimental data. Koble-Corrigan isotherm model consists of a combination between Langmuir and Freundlich models. More specifically, with the exponent $\mathrm{n}$ between 0 and 1 , the isotherm combines the properties of both Langmuir model and Freundlich model. While the value of $\mathrm{n}$ is close unlimitedly to 1.0, the isotherm is transformed into the Langmuir model ${ }^{21}$. From the $\mathrm{n}$ value of this study, it can be inferred that Koble-Corrigan isotherm resemble Langmuir model. Furthermore, high $\mathrm{R}^{2}$ values of above 0.995 and low $\chi^{2}$ error values of less than 0.0455 also suggested that Langmuir model had a better fit to the equilibrium data for all assessed temperatures. It should be noted that both $\mathrm{q}_{\mathrm{m}}$ and $\mathrm{K}_{\mathrm{L}}$ presented a small increase with the temperature, characterizing the endothermic nature of the adsorption process ${ }^{22}$.

The comparison of maximum monolayer adsorption of $\mathrm{MB}$ onto multifarious adsorbents is summarized in Table 6. As can be seen, the AP-PSC adsorbent exhibited a great potential for the removal of MB dye in aqueous solution.

\section{Adsorption thermodynamics}

The thermodynamic parameters $\left(\Delta \mathrm{G}^{0,} \Delta \mathrm{H}^{0}\right.$ and $\left.\Delta \mathrm{S}^{0}\right)$ and activation energy $\left(E_{a}\right)$ of the $M B$ adsorption on

Table 5. Parameters and determination coefficients of the isotherm models for the MB adsorption onto AP-PSC

\begin{tabular}{|c|c|c|c|c|}
\hline \multirow{2}{*}{ Model } & \multirow{2}{*}{ Parameters } & \multicolumn{3}{|c|}{ Temperature $\left[{ }^{\circ} \mathrm{C}\right]$} \\
\hline & & 25 & 35 & 45 \\
\hline \multirow{4}{*}{ Langmuir } & $\mathrm{K}_{\mathrm{L}} /\left[\mathrm{L} \mathrm{mg}^{-1}\right]$ & 0.165 & 0.183 & 0.226 \\
\hline & $\mathrm{q}_{\mathrm{m}} /\left[\mathrm{mg} \mathrm{g}^{-1}\right]$ & 368.2 & 376.6 & 381.4 \\
\hline & $\mathrm{R}^{2}$ & 0.996 & 0.995 & 0.995 \\
\hline & $x^{2}$ & 0.0333 & 0.0425 & 0.0455 \\
\hline \multirow{4}{*}{ Freundlich } & $\mathrm{K}_{\mathrm{F}} /\left[\mathrm{mg} \mathrm{g}^{-1}\left(\mathrm{~L} \mathrm{mg}^{-1}\right]^{1 / n}\right]$ & 254.7 & 262.3 & 271.5 \\
\hline & $1 / n$ & 0.0616 & 0.0611 & 0.0581 \\
\hline & $R^{2}$ & 0.825 & 0.891 & 0.877 \\
\hline & $x^{2}$ & 1.55 & 0.945 & 1.13 \\
\hline \multirow[t]{5}{*}{ Koble-Corrigan } & A & 36.8 & 109.3 & 134.8 \\
\hline & $B$ & 0.101 & 0.287 & 0.350 \\
\hline & $\mathrm{n}$ & 1.16 & 0.846 & 0.840 \\
\hline & $R^{2}$ & 0.999 & 0.998 & 0.998 \\
\hline & $x^{2}$ & 0.00993 & 0.0157 & 0.0120 \\
\hline
\end{tabular}


Table 6. Comparison of the maximum monolayer adsorption of MB onto various adsorbents

\begin{tabular}{|c|c|c|c|}
\hline Adsorbent & $\begin{array}{c}\mathrm{q}_{\mathrm{e}} \\
{\left[\mathrm{mg} \mathrm{g}^{-1}\right]}\end{array}$ & Conditions & Reference \\
\hline AP-PSC & 368.2 & $\mathrm{~m}: 0.5 \mathrm{~g} \mathrm{~L}^{-1}, \mathrm{~T}: 25^{\circ} \mathrm{C}, \mathrm{pH}: 5.3$ & This study \\
\hline Cellulose hydrogels & 172.14 & $\mathrm{~m}: 1.5 \mathrm{~g} \mathrm{~L}^{-1}, \mathrm{~T}: 30^{\circ} \mathrm{C}, \mathrm{pH}: 8$ & [23] \\
\hline $\mathrm{Fe}_{3} \mathrm{O}_{4} @ \mathrm{Ag} / \mathrm{SiO}_{2}$ nanosphere & 128.5 & $\mathrm{~m}: 0.6 \mathrm{~g} \mathrm{~L}^{-1}, \mathrm{~T}: 50^{\circ} \mathrm{C}, \mathrm{pH}: 7$ & [24] \\
\hline
\end{tabular}

AP-PSC were calculated using Van't Hoff plot and the Arrhenius equation respectively, as described in the following equations ${ }^{32}$ :

$\Delta G^{0}=-R T \ln K_{c}$

$K_{c}=q_{e} / C_{e}$

Where, $\Delta \mathrm{G}^{0}\left(\mathrm{~J} \mathrm{~mol}^{-1}\right), \mathrm{R}\left(8.314 \mathrm{~J} \mathrm{~mol}^{-1} \mathrm{~K}^{-1}\right)$ and $\mathrm{T}$ (K) represent Gibbs free energy change, the universal gas constant and the absolute temperature. $\mathrm{K}_{\mathrm{c}}$ is the equilibrium constant, which can be calculated from the intercept of Khan and Singh plot $\left(\ln \left(\mathrm{q}_{\mathrm{e}} / \mathrm{c}_{\mathrm{e}}\right)\right.$ versus $\left.\mathrm{q}_{\mathrm{e}}\right)$.

Van't Hoff equation: $\Delta G^{0}=\Delta H^{0}-T \Delta S$

Where entropy change $\Delta \mathrm{S}^{0}\left(\mathrm{~J} \mathrm{~mol}^{-1} \mathrm{~K}^{-1}\right)$ and enthalpy change $\Delta \mathrm{H}^{0}\left(\mathrm{~J} \mathrm{~mol}^{-1}\right)$ can be obtained from the slope and intercept of the Van't Hoff equation of $\Delta \mathrm{G}^{0}$ versus $\mathrm{T}$.

Arrhenius equation: $k=k_{0} e^{-E_{a} / R T}$

Where $\mathrm{k}\left(\mathrm{g} \mathrm{mg}^{-1} \mathrm{~min}^{-1}\right)$ is the pseudo-second-order rate constant, $\mathrm{k}_{0}\left(\mathrm{~g} \mathrm{mg}^{-1} \mathrm{~min}^{-1}\right)$ is the temperature-dependent factor, $\mathrm{E}_{\mathrm{a}}$ is the apparent activation energy of adsorption, $\mathrm{R}\left(8.314 \mathrm{~J} \mathrm{~mol}^{-1} \mathrm{~K}^{-1}\right)$ is the gas constant and $\mathrm{T}(\mathrm{K})$ is the adsorption absolute temperature. The linear form is:

$\ln k=-\frac{E_{a}}{R T}+\ln k_{0}$

When $\ln \mathrm{k}$ is plotted versus $1 / \mathrm{T}$, a straight line with slope $-E_{a} / R$ is obtained.

According to the results summarized in Table 7, the negative values of $\Delta G^{0}$ implied that the adsorption process could be spontaneous and thermodynamically favorable. The absolute values of $\Delta G^{0}$ became larger with the increase in temperature and this indicated the adsorption process favored at higher temperature. The positive entropy $\left(\Delta S^{0}\right)$ reflected the increase in randomness at the solid-liquid interface during the adsorption process. In addition, the positive value of enthalpy $\left(\Delta \mathrm{H}^{0}\right)$ confirmed that the adsorption process was endothermic, which was consistent with the equilibrium and kinetic data behavior. Further, the values of $\Delta \mathrm{G}^{0}$ (around -34.88 $\mathrm{KJ} \mathrm{mol}^{-1}$ ) indicated that the MB adsorption on AP-PSC involved both physical and chemical adsorption with the physisorption dominative $\mathrm{e}^{33}$. The low positive value of $E_{\mathrm{a}}$ suggested that the adsorption process was physical adsorption.

\section{Adsorption mechanism}

To gain better insight into the interaction mechanisms, the influence of $\mathrm{MB}$ solution $\mathrm{pH}$ on the adsorption capacity of AP-PSC was investigated. As shown in Fig. 5, the

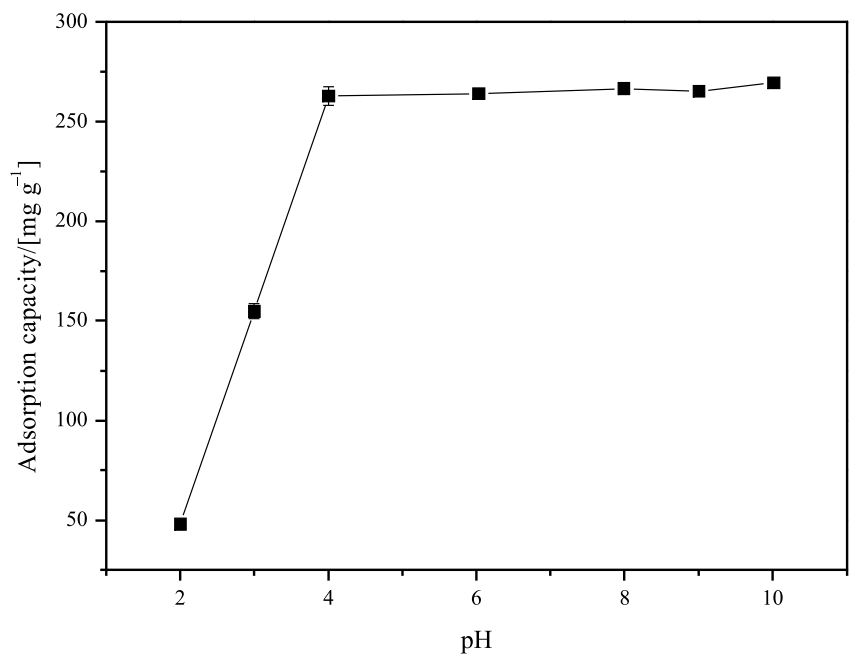

Figure 5. Effect of solution $\mathrm{pH}$ on the adsorption capacity of AP-PSC

adsorption capacity of AP-PSC rapidly increased at first and then remained at a certain level with an increase in the solution $\mathrm{pH}$. Initially, when the $\mathrm{pH}$ value of solution ranged from 2.0 to 4.0 , the positively charged amino groups in $\mathrm{MB}$ molecules become protonated and the excess of $\mathrm{H}^{+}$competes with cationic dye for adsorption sites. Therefore with the increase in $\mathrm{pH}$, the competition decreased and more MB molecules bound to the AP-PSC surface perhaps due to ion-exchange ${ }^{34}$, which was further confirmed by the inhibitory effect of solution salinity on $\mathrm{MB}$ adsorption (data not shown). However, it was found that the further increase of $\mathrm{pH}$ value(i.e. > 4.0) didn't induct the increase of the adsorption capacity of AP-PSC for MB but kept almost unchanged, which was possibly related to the saturation of adsorption sites ${ }^{35}$. Besides, even in strong acidic medium, a small amount of $\mathrm{MB}$ adsorption on the AP-PSC surface might be associated with the other intermolecular interactions such as Van der Waals forces and hydrogen bonds (Scheme 1). To sum up, the physisorption characteristics of adsorption

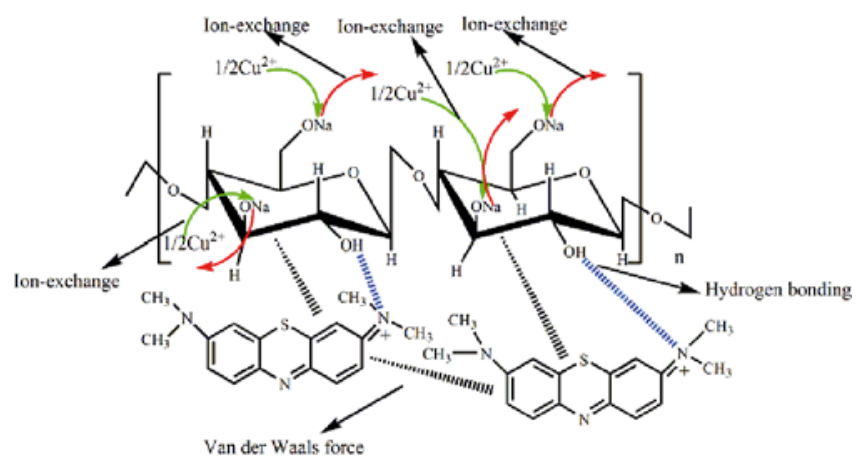

Scheme 1. The possible interactions between AP-PSC and MB

Table 7. Thermodynamic parameters and activation energy for the adsorption of MB on AP-PSC

\begin{tabular}{|l|c|c|c|}
\hline \multirow{2}{*}{$\begin{array}{l}\text { Temperature } \\
{[\mathrm{K}]}\end{array}$} & \multicolumn{3}{|c|}{ Parameters } \\
\cline { 2 - 4 } & $\Delta \mathrm{G}^{0}\left[\mathrm{KJ} \mathrm{mol}^{-1}\right]$ & $\Delta \mathrm{H}^{0}\left[\mathrm{KJ} \mathrm{mol}^{-1}\right]$ & $\Delta \mathrm{S}^{0}\left[\mathrm{KJ} \mathrm{mol}^{-1} \mathrm{~K}^{-1}\right]$ \\
\hline 308 & -32.13 & 63.30 & 0.32 \\
\hline 318 & -34.88 & & \\
\hline
\end{tabular}


process could well be relevant to ion-exchange, as well as Van der Waals forces and hydrogen bonds that occur concomitantly.

\section{CONCLUSION}

The $\mathrm{L}_{9}\left(3^{4}\right)$ orthogonal array design was successful in optimizing the process parameters for the alkali treatment. Maximum effectiveness of the pretreatment was achieved after treatment duration of 50 min with the LSR of $0.35 \mathrm{~L} \mathrm{~g} \mathrm{~g}^{-1}$ and in the presence of $0.8 \%(\mathrm{w} / \mathrm{w})$ $\mathrm{NaOH}$. Pseudo-second-order kinetic model was the best to describe kinetic process while Langmuir model and Koble-Corrigan model were available to fit the equilibrium data. Thermodynamic parameters revealed that the adsorption process was physical, endothermic and spontaneous. The maximum adsorption capacity was found to be $368.2 \mathrm{mg} \mathrm{g}^{-1}$ for $\mathrm{MB}$ at $25^{\circ} \mathrm{C}$. The significant improvement of AP-PSC adsorption capacity for MB may be attributed to the removal of lignin and hemicellulose, which will be verified in subsequent experiments. Finally, the AP-PSC adsorbent with its excellent adsorption capacity is truly a promising potential candidate in the future treatment of dyeing wastewater.

\section{CONFLICT OF INTEREST}

The authors declare that they have no conflict interest.

\section{ACKNOWLEDGEMENTS}

This work was financially supported by the National Natural Science Foundation of China (Grant No.: 21506197 and 21646011).

\section{LITERATURE CITED}

1. Sewu, D.D., Boakye, P. \& Woo, S.H. (2017). Highly efficient adsorption of cationic dye by biochar produced with Korean cabbage waste. J. Bioresour. Technol. 224, 206-213. DOI: 10.1016/j.biortech.2016.11.009.

2. Daneshvar, E., Vazirzadeh, A., Niazi, A., Sillanpää, M. \& Bhatnagar, A. (2017). A comparative study of methylene blue biosorption using different modified brown, red and green macroalgae-Effect of pretreatment. J. Chem. Eng. 307, 435-446. DOI: 10.1016/j.cej.2016.08.093.

3. Hethnawi, A., Nassar, N.N., Manasrah, A.D. \& Vitale, G. (2017). Polyethylenimine-functionalized pyroxene nanoparticles embedded on Diatomite for adsorptive removal of dye from textile wastewater in a fixed-bed column. J. Chem. Eng. 320, 389-404. DOI: 10.1016/j.cej.2017.03.057.

4. Bhatnagar, A., Sillanpää, M. \& Witek-Krowiak, A. (2015). Agricultural waste peels as versatile biomass for water purification-A review. J. Chem. Eng. 270, 244-271. DOI: 10.1016/j. cej.2015.01.135.

5. Anastopoulos, I., Karamesouti, M., Mitropoulos, A.C. \& Kyzas, G.Z. (2017). A review for coffee adsorbents. J. Mol. Liq. 229, 555-565. DOI: 10.1016/j.molliq.2016.12.096.

6. Cai, J., He,Y., Yu, X., Banks, S.W., Yang,Y., Zhang, X., Yu, Y., Liu, R. \& Bridgwater, A.V. (2017). Review of physicochemical properties and analytical characterization of lignocellulosic biomass. J. Renew. Sust. Energ. Rev. 76, 309-322. DOI: 10.1016/j.rser.2017.03.072.

7. Ummartyotin, S. \& Pechyen, C. (2016). Strategies for development and implementation of bio-based materials as effective renewable resources of energy: A comprehensive review on adsorbent technology. J. Renew. Sust. Energ. Rev. 62, 654-664. DOI: 10.1016/j.rser.2016.04.066.

8. Dai, Y., Zhang, D. \& Zhang, K. (2016). Nitrobenzene-adsorption capacity of $\mathrm{NaOH}$-modified spent coffee ground from aqueous solution. J. Taiwan Inst. Chem. Eng. 68, 232-238. DOI: $10.1016 /$ j.jtice.2016.08.042.

9. Messaoudi, N.E., Khomri, M.E., Bentahar, S., Dbik, A., Lacherai, A. \& Bakiz, B. (2016). Evaluation of performance of chemically treated date stones: Application for the removal of cationic dyes from aqueous solutions. J. Taiwan Inst. Chem. Eng. 67, 244-253. DOI: 10.1016/j.jtice.2016.07.024.

10. Zhang, X.X., Shi, Q.Q., Ji, D., Niu, L.X., Zhang, Y.L. (2017). Determination of the phenolic content, profile, and antioxidant activity of seeds from nine tree peony (Paeonia section Mountan DC.) species native to China. Food Res. Int. 97, 141-148. DOI: 10.1016/j.foodres.2017.03018.

11. Ma, L., Cui,Y., Cai, R., Liu, X., Zhang, C. \& Xiao, D. (2015). Optimization and evaluation of alkaline potassium permanganate pretreatment of corncob. J. Bioresour. Technol. 180, 1-6. DOI: 10.1016/j.biortech.2014.12.078.

12. Sun,Y.G., Ma,Y.L., Wang, L.Q., Wang, F.Z., Wu, Q.Q. \& Pan, G.Y. (2015). Physicochemical properties of corn stalk after treatment using steam explosion coupled with acid or alkali. J. Carbohydr. Polym. 117, 486-493. DOI: 10.1016/j. carbpol.2014.09.066.

13. Mohapatra, S., Dandapat, S.J. \& Thatoi, H. (2017). Physicochemical characterization, modelling and optimization of ultrasono-assisted acid pretreatment of two Pennisetum sp. using Taguchi and artificial neural networking for enhanced delignification. J. Environ. Manage 187, 537-549. DOI: 10.1016/j. jenvman.2016.09.060.

14. Gandolfi, S., Ottolina, G., Consonni, R., Riva, S. \& Patel, I. (2014). Fractionation of hemp hurds by organosolv pretreatment and its effect on production of lignin and sugars. J. ChemSusChem 7(7), 1991-1999. DOI: 10.1002/cssc.201301396.

15. Hameed, B.H. \& Ahmad, A.A. (2009). Batch adsorption of methylene blue from aqueous solution by garlic peel, an agricultural waste biomass. J. Hazard. Mater. 164(2-3), 870-875. DOI: 10.1016/j.jhazmat.2008.08.084.

16. Bulgariu, D. \& Bulgariu, L. (2016). Potential use of alkaline treated algae waste biomass as sustainable biosorbent for clean recovery of cadmium(II) from aqueous media: batch and column studies. J. Clean. Prod. 112(5), 4525-4533. DOI: 10.1016/j.jclepro.2015.05.124.

17. Ooi, J., Lee, L.Y., Hiew, B.Y.Z., Thangalazhy-Gopakumar, S., Lim, S.S. \& Gan, S. (2017). Assessment of fish scales waste as a low cost and eco-friendly adsorbent for removal of an azo dye: Equilibrium, kinetic and thermodynamic studies. J. Bioresour. Technol. 245, 656-664. DOI: 10.1016/j.biortech.2017.08.153.

18. Sayyadi, S., Ahmady-Asbchin, S., Kamali, K. \& Tavakoli, N. (2017). Thermodynamic, equilibrium and kinetic studies on biosorption of $\mathrm{Pb}^{2+}$ from aqueous solution by Bacillus pumilus sp. $\mathrm{AS}_{1}$ isolated from soil at abandoned lead mine. J. Taiwan Inst. Chem. Eng. 80, 701-708. DOI: 10.1016/j.jtice.2017.09.005.

19. Sarat Chandra, T., Mudliar, S.N., Vidyashankar, S., Mukherji, S., Sarada, R., Krishnamurthi, K. \& Chauhan,V.S. (2015). Defatted algal biomass as a non-conventional low-cost adsorbent: Surface characterization and methylene blue adsorption characteristics. J. Bioresour. Technol. 184, 395-404. DOI: 10.1016/j.biortech.2014.10.018.

20. Albadarin, A.B., Collins, M.N., Naushad, M., Shirazian, S., Walker, G. \& Mangwandi, C. (2017). Activated lignin-chitosan extruded blends for efficient adsorption of methylene blue. J. Chem. Eng. 307, 264-272. DOI: 10.1016/j.cej.2016.08.089.

21. Zhang, H., Li, A., Sun, J. \& Li, P. (2013). Adsorption of amphoteric aromatic compounds by hyper-cross-linked resins with amino groups and sulfonic groups. J. Chem. Eng. 217, 354-362. DOI: 10.1016/j.cej.2012.12.001.

22. Kumari, S., Chauhan, G.S. \& Ahn, J.H. (2016). Novel cellulose nanowhiskers-based polyurethane foam for rapid and 
persistent removal of methylene blue from its aqueous solutions. J. Chem. Eng. 304, 728-736. DOI: 10.1016/j.cej.2016.07.008.

23. Dai, H., Huang, Y. \& Huang, H. (2018). Eco-friendly polyvinyl alcohol/carboxymethyl cellulose hydrogels reinforced with graphene oxide and bentonite for enhanced adsorption of methylene blue. J. Carbohydr. Polym. 185, 1-11. DOI: 10.1016/j. carbpol.2017.12.073.

24. Saini, J., Garg,V.K. \& Gupta, R.K. (2018). Removal of Methylene Blue from aqueous solution by $\mathrm{Fe}_{3} \mathrm{O}_{4} @ \mathrm{Ag} /$ $\mathrm{SiO}_{2}$ nanospheres: Synthesis, characterization and adsorption performance. J. Mol. Liq. 250, 413-422. DOI: 10.1016/j.molliq.2017.11.180.

25. Cheng, M., Zeng, G., Huang, D., Lai, C., Liu,Y., Zhang, C., Wang, R., Qin, L., Xue,W., Song, B., Ye, S. \& Yi, H. (2018). High adsorption of methylene blue by salicylic acid-methanol modified steel converter slag and evaluation of its mechanism. J. coll. Interf. Sci. 515, 232-239. DOI: 10.1016/j.jcis.2018.01.008. 26. Guo, H., Bi, C., Zeng, C., Ma,W., Yan, L., Li, K. \& Wei, K. (2018). Camellia oleifera seed shell carbon as an efficient renewable bio-adsorbent for the adsorption removal of hexavalent chromium and methylene blue from aqueous solution. J. Mol. Liq. 249, 629-636. DOI: 10.1016/j.molliq.2017.11.096.

27. EL.-Mekkawi, D.M., Selim, Mohamed M. \& Ibrahim, Fatma A. (2018). Innovative synthesis of black zeolites-based kaolin and their adsorption behavior in the removal of methylene blue from water. J. Mater. Sci. 53(5), 3323-3331. DOI: 10.1007/s10853-017-1744-8.

28. Zhao, Q., Zhu, X. \& Chen, B. (2018). Stable graphene oxide/poly(ethyleneimine) 3D aerogel with tunable surface charge for high performance selective removal of ionic dyes from water. J. Chem. Eng. 334, 1119-1127. DOI: 10.1016/j. cej.2017.11.053.

29. Olusegun, S.J., de Sousa Lima, L.F. \& Mohallem, N.D.S. (2018). Enhancement of adsorption capacity of clay through spray drying and surface modification process for wastewater treatment. J. Chem. Eng. 334, 1719-1728. DOI: 10.1016/j. cej.2017.11.084.

30. Li, Z., Wang, G., Zhai, K., He, C., Li, Q. \& Guo, P. (2018). Methylene blue adsorption from aqueous solution by loofah sponge-based porous carbons. J. Colloid. Surface. A. 538, 28-35. DOI: 10.1016/j.colsurfa.2017.10.046.

31. Nasrullah, A., Bhat, A.H., Naeem, A., Isa, M.H. \& Danish, M. (2018). High surface area mesoporous activated carbon-alginate beads for efficient removal of methylene blue. J. Int. Biol. Macromol. 107, 1792-1799. DOI: 10.1016/j. ijbiomac.2017.10.045.

32. Han, R., Zhang, L., Song, C., Zhang, M., Zhu, H. \& Zhang, L. (2010). Characterization of modified wheat straw, kinetic and equilibrium study about copper ion and methylene blue adsorption in batch mode. J. Carbohydr. Polym. 79(4), 1140-1149. DOI: 10.1016/j.carbpol.2009.10.054.

33. Konicki, W., Aleksandrzak, M., Moszynski, D. \& Mijowska, E. (2017). Adsorption of anionic azo-dyes from aqueous solutions onto graphene oxide: Equilibrium, kinetic and thermodynamic studies. J. Coll. Interf. Sci. 496, 188-200. DOI: 10.1016/j.jcis.2017.02.031.

34. Patra, S., Roy, E., Madhuri, R. \& Sharma, P.K. (2016). Agar based bimetallic nanoparticles as high-performance renewable adsorbent for removal and degradation of cationic organic dyes. J. Ind. Eng. Chem. 33, 226-238. DOI: 10.1016/j. jiec.2015.10.008.

35. Esfandiyari, T., Nasirizadeh, N., Ehrampoosh, M.H. \& Tabatabaee, M. (2017). Characterization and absorption studies of cationic dye on multi walled carbon nanotube-carbon ceramic composite. J. Ind. Eng. Chem. 46, 35-43. DOI: 10.1016/j. jiec.2016.09.031. 